\title{
EVASÃO DE ESTUDANTES DOS CURSOS DE TURISMO E HOTELARIA DE UMA UNIVERSIDADE FEDERAL BRASILEIRA: MOTIVOS E CONSEQUÊNCIAS
}

\author{
David Leonardo Bouças da Silva \\ Universidade Federal do Maranhão - Brasil \\ Professor Departamento de Turismo e Hotelaria (DETUH/UFMA) \\ Doutor em Administração - PPGA/UnB \\ david.boucas@ufma.br \\ Lana Montezano \\ Universidade de Brasília. Brasil \\ Mestra e Doutoranda em Administração - PPGA/UnB \\ lanamontezano@gmail.com \\ Igor Carneiro de Almeida \\ Universidade Federal do Maranhão. Brasil \\ Mestrando em Turismo (EACH/USP) \\ Bacharel em Turismo - UFMA \\ carneiroigor01@gmail.com
}

\section{Resumo}

Objetivo: Identificar os motivos que levam à evasão de discentes dos cursos de Turismo e Hotelaria de uma universidade federal do Nordeste brasileiro, bem como investigar as suas percepções sobre o momento pós-evasão.

Metodologia: Trata-se de um estudo qualitativo, descritivo e exploratório, com 15 alunos evadidos dos cursos de Turismo e Hotelaria de uma IES pública, os quais foram selecionados pelos critérios de adesão e saturação teórica. A coleta de dados ocorreu por meio de entrevistas, com roteiro semiestruturado fundamentado na literatura específica, as quais foram gravadas, transcritas e submetidas à Análise de Conteúdo de Bardin (2011).

Originalidade/Relevância: Investiga o contexto de evasão específico de cursos de Hotelaria e Turismo, além de buscar compreender ganhos e perdas posteriores à evasão, sob a ótica dos evadidos, devido à carência de estudos com esta abordagem.

Principais resultados: A maioria dos discentes evadiu no primeiro ano do curso e não apresentava interesse prioritário na formação em Turismo ou Hotelaria. A evasão constitui um fenômeno multidimensional representado por oito motivos agrupados em duas categorias de fatores (Situacionais e Acadêmicos), sendo os mais recorrentes aqueles relacionados à carreira; dificuldade em conciliar estudo, trabalho e família; possuir ou iniciar outro curso; e razões de ordem familiar. No momento posterior à evasão, os entrevistados mencionaram tanto ganhos quanto perdas agrupadas em categorias acadêmico-profissionais e pessoais.

Contribuições: Permite identificar elementos relevantes ao tema da evasão que possam fornecer subsídios para as IES desenvolverem estratégias de permanência para os discentes.

Palavras-chave: Evasão. Motivos e Consequências. Turismo e Hotelaria. Ensino Superior. Universidade Federal.

\section{Cite como}

American Psychological Association (APA)

Bouças da Silva, D. L., Montezano, L., \& Almeida, I. C. de (2020). Evasão de estudantes dos cursos de turismo e hotelaria de uma universidade federal brasileira: motivos e consequências. PODIUM Sport, Leisure and Tourism Review, São Paulo, 9(2), 177-198. https://doi.org/10.5585/podium.v9i2.15853. 


\title{
DROPOUT OF STUDENTS FROM TOURISM AND HOSPITALITY COURSES OF A BRAZILIAN FEDERAL UNIVERSITY: REASONS AND CONSEQUENCES
}

\begin{abstract}
Purpose: Identify the reasons that lead to the dropout of students in the Tourism and Hospitality courses of a federal university in the Northeast of Brazil, as well as to investigate their perceptions about the post-dropout moment.
\end{abstract}

Methodology: This is a qualitative, descriptive and exploratory study, developed with 15 students that evaded from the Tourism and Hospitality courses of a public Higher Education Institution, selected by the adherence criteria and theoretical saturation. Data were collected through the application of a semi-structured script based on the specific literature, whose interviews were recorded, transcribed and submitted to Bardin's (2011) Content Analysis.

Originality/Relevance: The study investigates the dropout of students in the specific context of Hospitality and Tourism courses, and it seeks to understand the gains and losses arising from dropout. All this based on the perspective of these students, due to the lack of studies highlighting this approach.

Main results: Most of the students evaded in the first year of the course and they do not prioritize the formation in the Tourism or Hospitality courses. Dropout is a multidimensional phenomenon represented by eight reasons grouped into two categories of factors (Situational and Academic). The most recurring were those regarding to career; the difficulties in reconciling study, work and family; to own or to start another course; and due to family reasons. Subsequent to dropout, respondents mentioned both gains and losses grouped into academic-professional and personal categories.

Contributions: It allows identifying elements relevant to the dropout theme that can provide subsidies for the Higher Education Institutions to develop student retention strategies.

Keywords: Dropout. Reasons and Consequences. Tourism and Hospitality. Higher Education. Federal University.

\section{ABANDONO DE ESTUDIANTES DE TURISMO Y HOSTELERÍA DE UNA UNIVERSIDAD FEDERAL BRASILEÑA: RAZONES Y CONSECUENCIAS}

\section{Resumen}

Objetivo: Identificar las razones que conducen al abandono de los estudiantes de los cursos de Turismo y Hostelería de una universidad federal del Nordeste de Brasil, así como investigar sus percepciones sobre el momento después del abandono.

Metodología: Este es un estudio cualitativo, descriptivo y exploratorio, con 15 estudiantes evadidos de los cursos de Turismo y Hostelería de una IES pública, que fueron seleccionados por los criterios de adherencia y saturación teórica. La recogida de datos se realizó a través de entrevistas, con un guión semiestructurado basado en la literatura específica, que fueron registradas, transcritas y sometidas a la Análisis de Contenido de Bardin (2011).

Originalidad/Relevancia: Investiga el contexto del abandono específico de los cursos de Hostelería y Turismo, así como busca comprender las ganancias y pérdidas después del 
abandono, desde la perspectiva de los evadidos, en razón de la escasez de estudios con este enfoque.

Resultados principales: La mayoría de los estudiantes evadieron en el primer año del curso y no tenían interés prioritario en la formación en Hostelería o Turismo. El abandono es un fenómeno multidimensional representado por ocho razones agrupadas en dos categorías de factores (situacionales y académicos), en que los más recurrentes son aquellos relacionados con la carrera; dificultad para conciliar estudio, trabajo y familia; poseer o comenzar otro curso; y razones familiares. En el momento después del abandono, los encuestados mencionaron las ganancias y las pérdidas agrupadas en categorías académico-profesionales y personales.

Contribuciones: Permite identificar elementos relevantes para el tema del abandono que proporcionen subsidios para que las IES desarrollen estrategias de retención de los estudiantes.

Palabras-clave: Evasión. Razones y Consecuencias. Turismo y Hostelería. Enseñanza Superior. Universidad Federal.

\section{Introdução}

A ampliação das políticas de expansão do acesso e permanência à educação superior no Brasil gerou a necessidade de um acompanhamento sistemático da sua efetiva implantação (Santos Júnior \& Real, 2017). Esta expansão vem acompanhada do aumento da evasão, tanto no ensino presencial (Ambiel, 2015; Bardagi \& Hurtz, 2009), quanto à distância (Oliveira, Oesterreich, \& Almeida, 2018; Tae-dong et al., 2017), e este constitui um dos maiores desafios ao ensino superior (Barefoot, 2004; Chen, 2012; Santos, 2018).

Segundo dados do Instituto Nacional de Estudos e Pesquisas Educacionais Anísio Teixeira - INEP - (INEP, 2016, 2019), apenas 15,75\% dos que ingressaram no ensino superior, em 2014, concluíram seus cursos em 2018, inferindo-se, portanto, que os demais casos estão em situação de evasão, atraso ou trancamento de curso. Santos (2018) constatou que o número de concluintes é maior nas universidades privadas. Lima e Zago (2018), com base no Censo da Educação Superior de 2016, calcularam a taxa de sucesso de concluintes, em 2015, de apenas 42\%. E as taxas de evasão na Educação à Distância (EaD) são sempre superiores às do ensino presencial, seja no âmbito nacional (Oliveira et al., 2018) ou internacional (Tae-dong et al., 2017).

Dados específicos sobre cursos de Turismo e Hotelaria comprovam que, em 2018, existiam 120 deles ofertados por 72 instituições de ensino superior (IES) públicas brasileiras. Os dados indicaram um total de 17.754 alunos matriculados e 2.405 concluintes, o que representa, apenas, $16,25 \%$ dos que estavam matriculados no ano de 2015 . Neste mesmo ano, os cursos em comento apresentavam 1.366 matrículas trancadas, 3.707 desvinculadas, 77 alunos transferidos e 4 falecidos.

No contexto da Região Nordeste, em 2018, 18 IES públicas se distribuíam em 9 estados da federação, ofertando 25 cursos de Turismo e/ou Hotelaria. Nestes, havia 3.979 alunos matriculados e 440 concluintes, o que representa, proporcionalmente, uma taxa inferior aos índices nacionais (apenas 11,05\%). O número de matrículas trancadas nas IES públicas nordestinas foi de 331, além das 708 desvinculadas e 14 transferências para outros cursos 
(INEP, 2019). Estes números apontam para um cenário preocupante na permanência e conclusão de discentes de cursos superiores de Turismo e Hotelaria em IES públicas brasileiras, haja vista se tratar de um relevante setor econômico que, por vezes, carece de mão de obra mais qualificada e com competências específicas (Catramby \& Costa, 2004; Nieves, 2010).

Nesse cenário, reforça-se a relevância de políticas públicas que contribuam para a permanência dos discentes na educação superior brasileira, caso de programas como FIES, PROUNI, REUNI e PNAES (Lamers, Santos, \& Toassi, 2017; Lima \& Zago, 2018; Santos, 2018). Em meio a este esforço, carece-se de políticas públicas consistentes e contínuas que assegurem a permanência dos discentes na graduação (Cardoso \& Ludovico, 2017). A evasão requer especial atenção, porquanto afeta o resultado dos sistemas educacionais, devido às consequentes perdas sociais, acadêmicas e econômicas (Baggi \& Lopes, 2011; Silva Filho, Motejunas, Hipólito, \& Lobo, 2007; Sousa, Mártires, \& Sousa, 2018).

Ademais, traz-se que o fenômeno da evasão no ensino superior remete a uma complexidade intrínseca, em decorrência de uma diversidade de questões subjacentes, como pedagógicas, psicológicas, sociais, políticas, econômicas, administrativas, entre outras (Baggi \& Lopes, 2011; Santos Júnior \& Real, 2017). Nesse sentido, são requeridas investigações que lancem mão de múltiplos olhares interdisciplinares e em diferentes contextos (Almeida, Abbad, Meneses, \& Zerbini, 2013; Castro, Souza, \& Sá, 2019; Chen, 2012; Santos Júnior \& Real, 2017; Tae-dong et al., 2017).

A relevância deste trabalho encontra respaldo em Santos Jr. e Real (2017), para os quais muito ainda deve ser feito para enrobustecer a produção científica sobre evasão no ensino superior, sobretudo com enfoque interdisciplinar, que permita análises no conjunto das IES brasileiras e contribua com o campo das políticas educacionais. Além disso, estudos anteriores apontaram lacunas de pesquisa sobre a temática em questão (Ambiel, 2015; Ambiel, Carvalho, Moreira, \& Bacan, 2016; Baggi \& Lopes, 2011; Cardoso \& Ludovico, 2017), também no âmbito das universidades públicas (Sousa et al., 2018), o que reforça ainda ser este um terreno fértil de investigação.

No contexto específico da formação acadêmica em Turismo e Hotelaria, ressalva-se a importância de estudos sobre evasão, haja vista se ter identificado apenas dois trabalhos, publicados em periódicos internacionais, a respeito de motivos para o abandono. Em nenhum deles se tratou do momento pós-evasão. Essa constatação advém da busca em revisões de literatura sobre a temática (Santos Júnior \& Real, 2017), de pesquisas nas bases dos periódicos CAPES e SPELL, bem como das principais revistas científicas de Turismo indicadas pela Associação Nacional de Pesquisa e Pós-Graduação em Turismo (ANPTUR).

Ademais, destaca-se a retração das demandas por formação superior em Turismo e áreas afins (Mota \& Anjos, 2012; Sogayar \& Rejowski, 2011), apesar do movimento crescente na oferta de cursos técnico-profissionalizantes (Mota \& Anjos, 2012) e abertura de pós-graduações na área (Sogayar \& Rejowski, 2011). Problemas relacionados ao mercado de trabalho, como escassez de empregos estáveis, alto turnover (Rodriguez, González, \& RamosHenriquez, 2016), salários reduzidos e a baixa qualificação exigida (Tomazoni, 2007), repercutem na diminuição da demanda por esses cursos, os quais são, comumente, preteridos em relação a formações mais específicas, como a Gastronomia (Sogayar \& Rejowski, 2011), e tradicionais, como o Direito (Aranha \& Rocha, 2014).

Corroboram estes problemas, incongruências entre as estruturas curriculares dos cursos superiores e as reais necessidades do mercado de trabalho (Brandão \& Silva, 2018; Nieves, 2010). Ainda assim, as graduações na área seguem representando 64,3\% da oferta existente no Brasil (Pimentel, Carvalho, \& Pimentel, 2017). Acrescenta-se, ainda, a possível atuação de profissionais, no setor turístico, com qualquer formação (Petrizzi, Ollero, \& Pozo, 
2015), o que impacta as oportunidades de trabalho aos que possuem formações mais afins. Isto se justifica pelo fato das organizações turísticas almejarem, de forma crescente, pessoas com competências necessárias ao exercício laboral (Brandão \& Silva, 2018; Nieves, 2010), em vez de, propriamente, formações superiores específicas (Petrizzi et al., 2015).

Sendo assim, esta pesquisa objetivou identificar os motivos que levam à evasão de discentes dos cursos de Turismo e Hotelaria de uma universidade federal do Nordeste brasileiro, bem como investigar as suas percepções no momento pós-evasão. Este trabalho tem o potencial de identificar elementos relevantes ao tema da evasão que possam fornecer subsídios para as IES desenvolverem estratégias de permanência para os discentes, conforme recomendações de Vitória, Casartelli, Rigo e Costa (2018).

Considerando, ainda, a relevância da formação e da oferta de profissionais qualificados e em quantidade suficiente para atender às demandas do mercado de trabalho (Petrizzi et al., 2015; Sogayar \& Rejowski, 2011), busca-se gerar contributos que subsidiem a melhoria na prestação dos serviços turísticos no contexto nacional.

\section{Referencial teórico}

\subsection{Evasão no ensino superior: conceitos, motivos e estratégias de retenção}

O conceito de evasão apresenta posicionamentos controversos, pois se confunde com outros aspectos associados à mobilidade estudantil (Lima \& Zago, 2018). Para resolver esta problemática, o Ministério da Educação (Brasil, 1996) propôs três definições distintas de evasão: de curso (quando abandona ou não se matricula no curso que participava e emigra para outro na mesma IES), de instituição (quando não renova a matrícula na IES e emigra para outra) e do sistema (quando abandona, temporariamente ou definitivamente, o ensino superior). A partir da revisão de literatura sobre o tema, Baggi e Lopes (2011) consolidaram a sua definição da evasão como a saída do discente antes de concluir o curso. Castro et al. (2019) corroboraram esta visão ao proferirem que a evasão ocorre quando o alunado abandona ou desiste do curso que estava matriculado antes de sua conclusão.

Como motivos da evasão são considerados aqueles que levam os discentes à tomada de decisão sobre o desligamento, em caráter temporário ou definitivo, do curso superior, podendo ocorrer de maneira isolada ou por uma combinação desses motivos (Sousa et al., 2018). A evasão afeta os estudantes de maneira distinta, dependendo de uma série de fatores como o seu grau de maturidade e o preparo para a vida universitária. Enquanto a decisão pode ser permanente para uns, outros evadem, temporariamente, para refletir sobre suas decisões acadêmico-profissionais (Barefoot, 2004). A evasão, portanto, deve ser compreendida como um fenômeno multidimensional, dada a pluralidade de fatores que influenciam essa decisão (Almeida et al., 2013; Sousa et al., 2018). Para o indivíduo, evadir pode significar o fim do ensejo de uma formação universitária, com comprometimento de seus rendimentos futuros. Para as IES, implica em custos de oportunidade por conta da vaga ociosa (Sampaio, Sampaio, Melo, \& Melo, 2011). A seguir, serão expostos resultados de investigações sobre evasão no ensino superior em diferentes contextos.

Em pesquisa sobre os determinantes da evasão em IES privada, Silva (2013) constatou que o risco da evasão é mais elevado nos semestres iniciais e diminui no decorrer do curso, sendo a maior ocorrência do primeiro para o segundo semestre. $\mathrm{O}$ autor identificou variáveis que precipitam a evasão, como a reprovação em disciplinas e aspectos financeiros. Barefoot (2004) justificou a evasão nos primeiros anos da formação, devido à insatisfação com atividades e conteúdos desenvolvidos. Na contramão, Silva Filho et al. (2007) verificaram que 
a falta de recursos financeiros, embora, comumente, manifestadas por IES e estudantes, é uma simplificação desses motivos. Para eles, aspectos acadêmicos são os mais relevantes, como a expectativa discente quanto à formação e a sua falta de integração com a instituição. Para alunos de baixa renda, Melguizo, Torres e Jaime (2011) asseveraram que os financiamentos são condição sine qua non para que o alunado persista nos estudos.

Bardagi e Hutz (2009), em pesquisa junto a graduandos evadidos de IES porto alegrenses, identificaram dois perfis: os insatisfeitos desde o ingresso no curso e os que ficam insatisfeitos ao longo dele. Os motivos centrais da evasão foram fragilidade na escolha do curso, falta de expectativas com a carreira, desconhecimento da realidade do trabalho vinculada à formação, problemas de relacionamentos com colegas e professores, percepção de abandono e descaso da IES, e estilo de vida de pessoas e ambientes da área de formação. Constataram, ainda, baixa insatisfação quanto à decisão de evadir, sugerindo que a orientação vocacional no ensino médio favoreceria melhores decisões na escolha do curso. Por outro lado, Barlem et al. (2012) expuseram que a evasão pode gerar sensação de arrependimento, principalmente, quando o alunado não consegue ingressar em outro curso superior e passa a temer que sua ascensão social não ocorra.

Lamers et al. (2017) estudaram os motivos da retenção e evasão de estudantes de Odontologia em uma IES pública, e definiram cinco categorias emergentes: chegada e adaptação à rotina universitária; necessidade de conciliar trabalho e estudo; importância das vivências em sala de aula e habilidade didático-pedagógica do docente; processos de avaliação de aprendizagem adequados; e papel da IES na retenção do alunado, quanto à distribuição, organização e oferta de disciplinas, disponibilidade de infraestrutura (laboratórios, salas de aula etc.).

Cardoso e Ludovico (2017) constataram que $78 \%$ das dissertações e teses publicadas no Brasil que investigaram o tema, realizaram diagnóstico dos motivos da evasão e propuseram ações para evitá-la. Assim, verificaram três tipos de fatores que levam à evasão: fatores internos à IES (infraestrutura, corpo docente, práticas metodológicas de ensino, questões administrativas, assistência socioeducacional); fatores externos à IES (políticas públicas de permanência); fatores individuais dos estudantes (erro na escolha do curso, imaturidade, contexto pessoal e familiar, expectativas profissionais e aspectos financeiros).

Santos (2018) manifestou como motivos para a evasão na Universidade Federal de Uberlândia: cansaço, desânimo, falta de perspectivas e dificuldades de acompanhar os conteúdos. Castro et al. (2019), na pesquisa com graduandos de diferentes licenciaturas, em uma IES federal da Região Centro-Oeste, definiram: fatores internos/institucionais (aulas, coordenação, curso, ensino, horários, professores e transporte) e fatores externos (família, matérias oferecidas, problemas pessoais, realização pessoal, realização profissional, tempo, trabalho, mudança de curso). As razões para evadir se relacionaram aos docentes, coordenação, ensino e aulas.

Ambiel (2015) desenvolveu uma escala de motivos para evasão do ensino superior, composta por 65 itens agrupados em sete fatores: aspectos institucionais (corpo docente, oferta de serviços e infraestrutura); motivos pessoais (incerteza da escolha do curso e aspectos familiares); falta de suporte (aspectos financeiros e dificuldade de conciliar estudos e trabalho); motivos relacionados à carreira (perspectivas de mercado de trabalho e satisfação com a profissão); motivos de desempenho acadêmico (resultados nas disciplinas); motivos interpessoais (dificuldades de relacionamento com colegas), e motivos relacionados à autonomia (problemas por não morar com a família). Bardagi e Hutz (2012) notaram que os motivos interpessoais foram os mais relevantes para que alunos de Porto Alegre postergassem a evasão ou de fato evadissem, conforme avaliação positiva ou negativa dos relacionamentos com colegas e/ou docentes. 
A fim de verificar diferenças de motivos por perfil de discentes, Ambiel et al. (2016) concluíram que dificuldades financeiras impactam mais alunos de IES privadas do que públicas, dado os custos das mensalidades. As razões centrais nas públicas remetem ao contexto institucional, como questões acadêmicas, falta de estrutura física e de suporte familiar. Em complemento, Ziliotto, Souza e Andrade (2018), na investigação junto a discentes com deficiência auditiva, verificaram que estes sofrem, desde o início da formação, com realocações dos intérpretes de Libras, o que justifica, em parte, a evasão. Chim-Miki, Campos e Melo (2019) indicaram que o abandono do curso de Administração da Universidade Federal de Campina Grande, justifica-se pelo ambiente acadêmico desfavorável, no que concerne a salas de aula inadequadas à interação, criatividade e aprendizagem.

No contexto internacional, Barefoot (2004) relatou que, na realidade de muitos países, preparação acadêmica, condições socioeconômicas e envolvimento familiar são preditores da permanência na educação superior. Ishitani e DesJardins (2002) comprovaram, em uma faculdade norte-americana, que estudantes com menor renda familiar apresentam maiores probabilidades de evasão. Estes achados vão ao encontro dos de Melguizo et al. (2011), acerca das razões principais entre universitários colombianos.

Xu (2017) observou que os discentes de uma universidade do sudeste dos Estados Unidos permanecem ou não no curso devido a fatores acadêmicos e sociais. Sob outro prisma, Sousa et al. (2018) verificaram que dificuldade financeira foi o fator menos predominante para graduandos da Universidade de Portugal, embora tenham encontrado alta correlação entre evasão e renda. Neste estudo, a dimensão profissional apresentou a maior média dos motivos de evasão, e a combinação de motivos individuais - maternidade, problemas de saúde e familiares - e institucionais - aprovação em outra IES, reprovações em disciplinas também respondeu por ela.

Em se tratando, estritamente, da evasão dos cursos de Turismo e Hotelaria, reafirma-se a escassez de publicações, em periódicos, que abordem os seus motivos, assim como a ausência daquelas que tratam das percepções dos evadidos no momento pós-abandono. A busca por literatura específica possibilitou o conhecimento de dois estudos, quais sejam: Wickens, Forbes e Tribe (2006) estudaram as razões da evasão em uma IES inglesa e verificaram que a qualidade dos relacionamentos interpessoais, com seus pares e tutores, além do suporte familiar e o senso de liberdade foram determinantes na permanência ou abandono dos cursos de Turismo e afins. Anastasiou (2019), por sua vez, pesquisou estudantes do Chipre e também constatou que aspectos relacionais são fundamentais na decisão de permanecer no curso, mais do que questões intrapessoais como aspirações financeiras ou experiências profissionais desejadas.

Nos cursos com metodologia de Educação à Distância $(\mathrm{EaD})$, a investigação de Almeida et al. (2013), na Universidade de Brasília, detectou quatro categorias de motivos: fatores situacionais (problemas de saúde ou familiares; interesse em outro curso; dificuldade em conciliar trabalho, estudo e família; falta de apoio no trabalho, de tempo para estudar e de organização para o estudo); fatores acadêmicos (falta de apoio/feedback do tutor, de interação na relação aluno-professor e de contato com o tutor); fatores tecnológicos e de infraestrutura (envio de trabalhos por fax/correio; falta de computador, de acesso à internet e de habilidade para uso da tecnologia); e fatores administrativos (logística de distribuição de material, prazos curtos para tarefas e informações imprecisas sobre o curso).

Em consonância ao estudo anterior, Oliveira et al. (2018) descobriram que, inclusive nas pós-graduações à distância, a evasão ocorre por motivos familiares, de saúde e falta de tempo, e esta situação agrava para cursos com menor duração - especializações - e quanto mais velhos forem os discentes. Para Netto, Guidotti e Santos (2012), apesar das vantagens da $\mathrm{EaD}$, problemas financeiros, falta de tempo, não adaptação ao método, crença de que a EaD é 
mais fácil, afora a obrigatoriedade das provas presenciais podem levar à evasão. No cenário internacional, Tae-dong et al. (2017) resumiram fatores da evasão na EaD em muitos países, como a falta de conhecimento prévio dos conteúdos abordados, de motivação para permanecer engajado nas atividades, e de interação com colegas e tutores. Ainda que os contextos sejam distintos, são observadas similaridades nas causas da evasão, tanto em cursos EaD quanto presenciais.

No que tange às estratégias para mitigar a evasão, Ishitani e DesJardins (2002) propuseram realizar a análise histórica dos estudantes - renda, grau de formação dos pais etc. - a fim de identificar o perfil daqueles sob risco de evasão. Assim como Melguizo et al. (2011), aqueles autores reforçaram que subsídios financeiros configuram estratégia eficaz na redução das taxas de evasão. Outros estudos investigaram o processo de engajamento acadêmico, cuja responsabilidade é do discente e da IES (Vitória et al., 2018). Por parte do alunado, espera-se seu engajamento afetivo (desejo de aprender), cognitivo (mobilização intelectual para a aprendizagem) e comportamental (assiduidade, participação, realização das atividades). Sob o prisma institucional, indicou-se promover inovações didático-pedagógicas, acompanhar o engajamento dos discentes, além de oferecer infraestrutura adequada, suporte docente e atividades teórico-práticas.

Chen (2012) reforçou esta recomendação ao identificar correlação negativa entre serviços de apoio prestados aos universitários americanos - fomento a eventos culturais, jornais estudantis, práticas esportivas etc. - e o risco de evasão. Xu (2017) destacou a necessidade de melhorar o ambiente de aprendizagem, a qualidade acadêmica e reduzir as preocupações financeiras do alunado para manter o seu interesse nos estudos. Chim-Miki et al. (2019) recomendaram a oferta de espaços criativos e estimulantes com abordagens de inovação educativa institucional, curricular e didática.

Oliveira et al. (2018) sugeriram, para as pós-graduações à distância, situações como o alargamento dos prazos de conclusão, tutores de acompanhamento, antecipação de disciplinas específicas para o primeiro semestre e flexibilização das datas de provas. Tae-dong et al. (2017) aconselharam que a $\mathrm{EaD}$ seja mais rígida e limite o número de acessos dos estudantes aos materiais/aulas para fortalecer o seu compromisso e a sua concentração. Seja no ensino presencial (Barefoot, 2004) ou na EaD (Oliveira et al., 2018), embora as estratégias de retenção não sejam totalmente eficazes, a sua ausência corrobora as taxas de evasão.

\section{Metodologia}

Esta pesquisa utiliza abordagem qualitativa e se caracteriza como descritivoexploratória (Flick, 2009), dada as suas contribuições na descrição do fenômeno da evasão no ensino superior, em especial dos cursos de Turismo e de Hotelaria. A escolha por um estudo qualitativo visou suprir lacuna quanto a este tipo de abordagem em investigações sobre evasão indicadas por Bardagi e $\operatorname{Hurtz}$ (2009, 2012), de modo a permitir maior aprofundamento do fenômeno.

A população da pesquisa foram os evadidos, entre os semestres 2010.1 e 2019.1, dos referidos cursos pertencentes a uma universidade federal da Região Nordeste. Os dados obtidos, nas Coordenações de Turismo e de Hotelaria desta instituição, indicaram que, entre 2009.1 e 2018.2, evadiram destes cursos 1.197 e 935 alunos, respectivamente. Nas universidades nordestinas, de maneira geral, houve uma média de $21 \%$ de taxa de evasão entre 2000 e 2005 (Silva Filho et al., 2007). Para a identificação dos potenciais respondentes da pesquisa, buscou-se o contato dos evadidos com professores e discentes dos referidos cursos, afora a publicação nas redes sociais dos autores, convidando para participar do estudo. 
Na determinação dos informantes, foram utilizados os critérios de adesão e saturação teórica (Fontanella, Ricas, \& Turato, 2008), chegando ao quantitativo de 15 entrevistados.

A coleta de dados, realizada entre fevereiro e abril de 2019, lançou mão de roteiro semiestruturado, cuja elaboração se pautou, principalmente, em Almeida et al. (2013), Ambiel (2015), Bardagi e Hutz (2012). O instrumento foi composto por três blocos: i. Caracterização dos entrevistados, contendo 17 itens de perfil sociodemográficos, profissionais e informações gerais sobre a evasão (ano, tipo de evasão, como evadiu); ii. Motivos da evasão, com cinco questões abertas; iii. Momento pós-evasão, com quatro questões abertas. As entrevistas foram realizadas presencialmente, por Skype ou por áudio do Whatsapp, a fim de conciliar a agenda dos voluntários. As entrevistas foram gravadas com consentimento dos participantes, após explicação do tema da pesquisa e da garantia do sigilo das informações. Em seguida, foram transcritas em Word, totalizando um corpus de 26.495 palavras e 87 páginas.

Os dados foram submetidos à técnica de Análise de Conteúdo de Bardin (2011) - esta fortemente recomendada na literatura do turismo (Sousa \& Tomazzoni, 2017) - em que se realizou a leitura flutuante para visão geral dos dados, agrupados por núcleos de sentido para definição das categorias temáticas. Na categorização a posteriori, fez-se uso da teoria para o estabelecimento dessas categorias. Em seguida, houve triangulação de pesquisadores para validação dos resultados, a fim de discutir e adequar os resultados finais, os quais foram comparados com achados da produção científica.

\section{Análise e discussão dos resultados}

\subsection{Caracterização da amostra}

Com relação ao perfil dos 15 entrevistados, tem-se que 11 são do sexo feminino e 4 do masculino, com idade média de 27,8 anos $(\mathrm{DP}=8,65$; Min $=19$; Máx $=47)$. Em relação à escolaridade, nove deles ainda não finalizaram o ensino superior e os demais concluíram outros cursos, sendo que quatro fizeram pós-graduação. Tem-se ainda que sete entrevistados são estudantes, enquanto os demais trabalham. Em relação ao vínculo com a universidade no momento da evasão, cinco eram cotistas e dez não; havia apenas um bolsista; nove cursavam turismo e seis hotelaria. Em complemento, elaborou-se a Tabela 1, contendo as informações do primeiro bloco do roteiro de entrevista, relativo à caracterização da amostra. 
Tabela 1 - Caracterização dos entrevistados

\begin{tabular}{|c|c|c|c|c|c|c|}
\hline $\mathbf{N}^{\mathbf{o}}$ & Ocupação & $\begin{array}{l}\text { Curso que } \\
\text { evadiu }\end{array}$ & $\begin{array}{c}1^{\text {a }} \text { opção no } \\
\text { ENEM } \\
\text { Vestibular }\end{array}$ & $\begin{array}{l}\text { Semestre/ } \\
\text { Ano da } \\
\text { evasão }\end{array}$ & Tipo de evasão & $\begin{array}{c}\text { Escolaridade } \\
\text { atual }\end{array}$ \\
\hline E1 & Autônoma & Turismo & Turismo & $1 \% / 2016$ & $\begin{array}{c}\text { Curso } \\
\text { Trancamento }\end{array}$ & $\begin{array}{l}\text { Superior } \\
\text { completo }\end{array}$ \\
\hline E2 & Estudante & Hotelaria & Direito & $1 \% / 2018$ & $\begin{array}{c}\text { Curso } \\
\text { Transf.Interna }\end{array}$ & $\begin{array}{c}\text { Superior } \\
\text { incompleto }\end{array}$ \\
\hline $\mathbf{E 3}$ & Estudante & Turismo & Computação & $1 \% / 2014$ & $\begin{array}{c}\text { Curso } \\
\text { Transf.Interna }\end{array}$ & $\begin{array}{c}\text { Superior } \\
\text { incompleto }\end{array}$ \\
\hline E4 & $\begin{array}{c}\text { Professora } \\
\text { Corretora }\end{array}$ & Hotelaria & Hotelaria & $1 \% / 2018$ & $\begin{array}{l}\text { Abandono } \\
\text { Ens.Superior }\end{array}$ & Pós-graduação \\
\hline E5 & Estudante & Hotelaria & História & $1 \% / 2018$ & $\begin{array}{c}\text { Curso } \\
\text { Transf.Interna }\end{array}$ & $\begin{array}{c}\text { Superior } \\
\text { incompleto }\end{array}$ \\
\hline E6 & Estudante & Turismo & $\begin{array}{c}\text { Serviço } \\
\text { Social }\end{array}$ & $2^{\circ} / 2018$ & $\begin{array}{c}\text { Curso } \\
\text { Cancelamento }\end{array}$ & $\begin{array}{c}\text { Superior } \\
\text { incompleto }\end{array}$ \\
\hline E7 & Estudante & Hotelaria & Contábeis & $2^{\circ} / 2014$ & $\begin{array}{l}\text { Abandono } \\
\text { Curso/IES }\end{array}$ & $\begin{array}{c}\text { Superior } \\
\text { incompleto }\end{array}$ \\
\hline E8 & $\begin{array}{l}\text { Operador de } \\
\text { telemarketing }\end{array}$ & Hotelaria & História & $7^{\circ} / 2015$ & $\begin{array}{c}\text { Abandono } \\
\text { Ens.Superior }\end{array}$ & $\begin{array}{c}\text { Superior } \\
\text { incompleto }\end{array}$ \\
\hline E9 & $\begin{array}{l}\text { Atendimento e } \\
\text { Vendas }\end{array}$ & Turismo & Jornalismo & $5 \% / 2016$ & $\begin{array}{l}\text { Abandono } \\
\text { Curso/IES }\end{array}$ & $\begin{array}{c}\text { Superior } \\
\text { incompleto }\end{array}$ \\
\hline E10 & $\begin{array}{c}\text { Assistente } \\
\text { administrativo }\end{array}$ & Turismo & Turismo & $2^{\circ} / 2018$ & $\begin{array}{c}\text { Abandono } \\
\text { Ens.Superior }\end{array}$ & $\begin{array}{c}\text { Superior } \\
\text { incompleto }\end{array}$ \\
\hline E11 & Professor & Hotelaria & Hotelaria & $8^{\circ} / 2019$ & $\begin{array}{c}\text { Abandono } \\
\text { Ens.Superior }\end{array}$ & Pós-graduação \\
\hline E12 & Servidor público & Turismo & Computação & $2^{\circ} / 2010$ & $\begin{array}{l}\text { Abandono } \\
\text { Curso/IES }\end{array}$ & Pós-graduação \\
\hline E13 & Estudante & Turismo & $\begin{array}{c}\text { Educação } \\
\text { Física }\end{array}$ & $1 \% / 2018$ & $\begin{array}{c}\text { Curso } \\
\text { Transf.Interna }\end{array}$ & $\begin{array}{l}\text { Superior } \\
\text { completo }\end{array}$ \\
\hline E14 & Estudante & Turismo & Biologia & $1^{\circ} / 2015$ & $\begin{array}{c}\text { Curso } \\
\text { Transf.Interna }\end{array}$ & $\begin{array}{c}\text { Superior } \\
\text { incompleto }\end{array}$ \\
\hline E15 & $\begin{array}{l}\text { Servidora } \\
\text { pública }\end{array}$ & Turismo & Turismo & $1 \% / 2018$ & $\begin{array}{c}\text { Abandono } \\
\text { Ens.Superior }\end{array}$ & Pós-graduação \\
\hline
\end{tabular}

Fonte: Elaboração própria baseada nos dados da pesquisa.

A partir da Tabela acima, observa-se que os respondentes evadiram entre 2010 e 2019. A maioria (12) evadiu no primeiro ano do curso, sendo que oito saíram ao final do primeiro semestre e quatro no final do segundo semestre. Este resultado expressa os achados de pesquisa que indicam a evasão como uma prática mais comum entre o primeiro e o segundo semestre (Silva, 2013), ou até o segundo ano do curso (Barefoot, 2004). Entre os tipos de evasão, cinco realizaram transferência interna e indicaram esta intenção desde o início do curso, conforme verificado por Bardagi e Hutz (2009). Além disso, cinco não retomaram a educação superior e seis mudaram de curso, mas permaneceram na mesma IES. Para estas evasões, identificou-se um desligamento, dois cancelamentos, seis abandonos e seis trancamentos.

Dos respondentes, oito não indicaram Turismo ou Hotelaria como primeira opção no Enem/Vestibular. Em vez disso: Direito, Computação, História, Serviço Social, Contábeis, Jornalismo, Educação Física e Biologia. A este respeito, já se havia indicado que cursos de Turismo e afins sejam, ceteris paribus, preteridos em relação a formações mais específicas e tradicionais (Aranha \& Rocha, 2014; Sogayar \& Rejowski, 2011). 


\subsection{Motivos da evasão}

Em se tratando dos motivos da evasão, os depoimentos foram analisados e agrupados em duas categorias temáticas que congregam os oito motivos (subcategorias) da evasão: Fatores Situacionais, com sete motivos, e Fatores Acadêmicos, com um motivo. Tem-se ainda que, dos situacionais, três foram considerados somente como motivo principal, um somente como secundário, e três como principal e secundário. Subsequentemente, serão apresentadas as categorias e suas respectivas definições constitutivas, os motivos, a origem do motivo (principal ou secundária), exemplo de relatos, quem citou cada motivo e os achados correlatos na literatura (Tabela 2). 
Tabela 2 - Motivos Principais e Secundários da Evasão

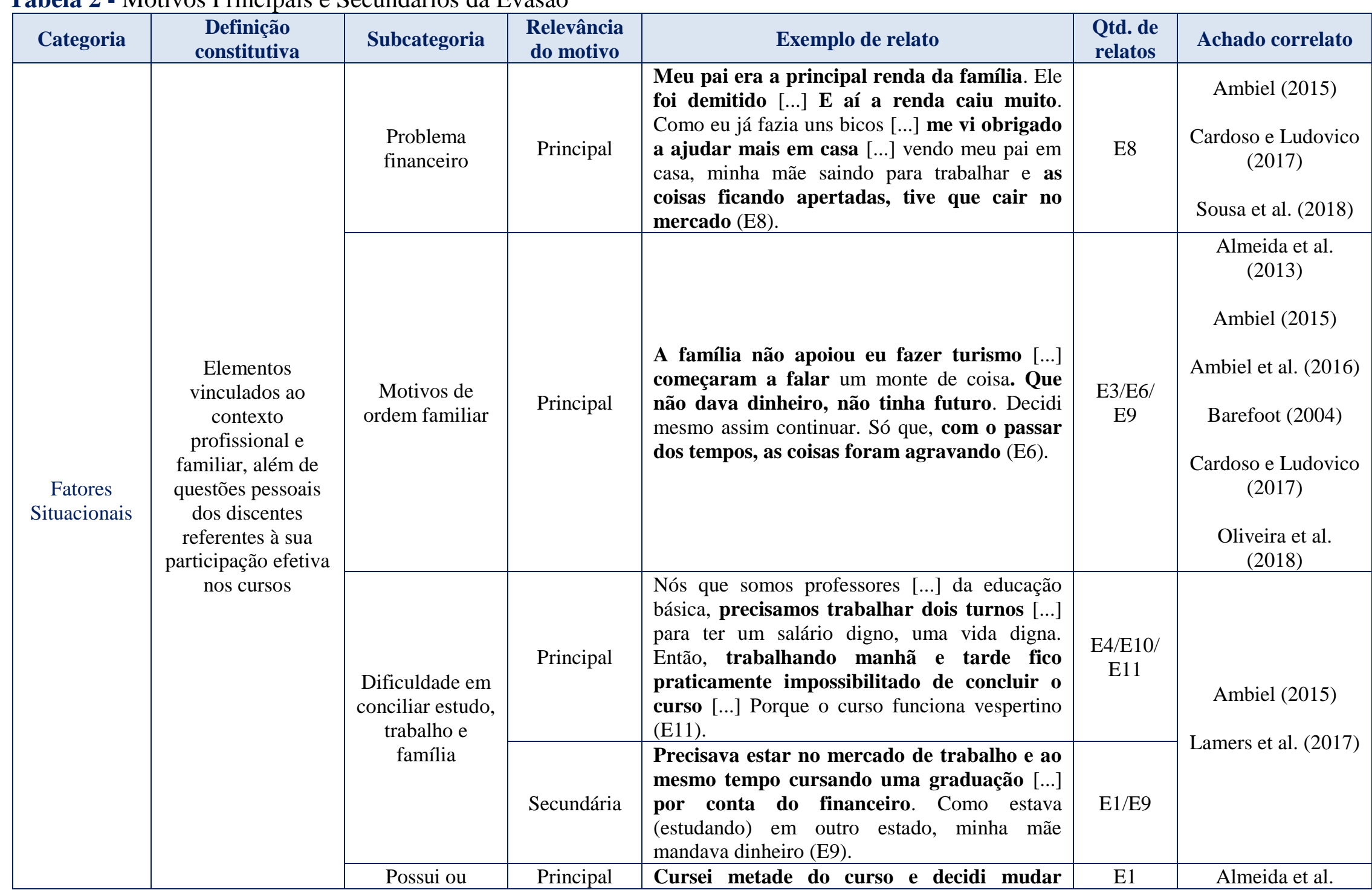




\begin{tabular}{|c|c|c|c|c|c|c|}
\hline Categoria & $\begin{array}{l}\text { Definição } \\
\text { constitutiva }\end{array}$ & Subcategoria & $\begin{array}{l}\text { Relevância } \\
\text { do motivo }\end{array}$ & Exemplo de relato & $\begin{array}{l}\text { Qtd. de } \\
\text { relatos }\end{array}$ & Achado correlato \\
\hline \multirow{6}{*}{$\begin{array}{l}\text { Fatores } \\
\text { Situacionais } \\
\quad \text { (cont.) }\end{array}$} & & \multirow[t]{2}{*}{$\begin{array}{l}\text { iniciou outro } \\
\text { curso }\end{array}$} & & $\begin{array}{l}\text { porque fiz vestibular novamente e passei para } \\
\text { Computação (E1). }\end{array}$ & & \multirow[t]{2}{*}{ (2013) } \\
\hline & & & Secundária & $\begin{array}{l}\text { Evadi várias vezes. } 2018 \text { e } 2019 \text { [...] por conta } \\
\text { do mestrado [...] a gente precisa de formação } \\
\text { continuada (E11). }\end{array}$ & $\begin{array}{l}\text { E4/E11/ } \\
\text { E12 }\end{array}$ & \\
\hline & & \multirow{2}{*}{$\begin{array}{l}\text { Motivos } \\
\text { relacionados à } \\
\text { carreira }\end{array}$} & Principal & $\begin{array}{l}\text { Não enxergava grandes oportunidades para a } \\
\text { profissão de turismólogo }[\ldots] \text { sempre escutei } \\
\text { comentários ruins a respeito da área }[. . .] \text { tive } \\
\text { outra oportunidade para assumir um cargo } \\
\text { público }[. . .] \text { Então, naquele momento, optei por } \\
\text { abandonar o curso (E12). }\end{array}$ & $\begin{array}{l}\text { E2/E5/ } \\
\text { E12/E13/ } \\
\quad \text { E14 }\end{array}$ & \multirow{2}{*}{$\begin{array}{c}\text { Ambiel (2015) } \\
\text { Bardagi e Hutz } \\
\text { (2009) } \\
\text { Cardoso e Ludovico } \\
\text { (2017) }\end{array}$} \\
\hline & & & Secundária & $\begin{array}{l}\text { Outra coisa que me fez desistir também }[\ldots] \\
\text { língua estrangeira }[\ldots] \text { acabei me } \\
\text { desmotivando. E o mercado de trabalho }[\ldots] \\
\text { Pouco emprego e o salário não é tão bom } \\
\text { (E6). }\end{array}$ & $\begin{array}{l}\text { E6/E7/ } \\
\text { E8/E9 }\end{array}$ & \\
\hline & & $\begin{array}{l}\text { Intenção prévia } \\
\text { de mudança de } \\
\text { curso }\end{array}$ & Principal & $\begin{array}{l}\text { O principal motivo foi porque não era a } \\
\text { minha primeira opção }[\ldots] \text { sempre almejei } \\
\text { Contábeis }[\ldots] \text { me inscrevi na Hotelaria que era } \\
\text { o que a minha nota dava (E7). }\end{array}$ & E7 & $\begin{array}{l}\text { Bardagi e Hutz } \\
\quad(2009)\end{array}$ \\
\hline & & $\begin{array}{l}\text { Problema de } \\
\text { saúde }\end{array}$ & Secundária & $\begin{array}{l}\text { Também por questão de saúde. Estresse e } \\
\text { ansiedade por conta do emprego no mercado } \\
\text { imobiliário [...] exige muito tempo [...] muitas } \\
\text { atividades (E4). }\end{array}$ & $\mathrm{E} 4$ & $\begin{array}{l}\text { Almeida et al. } \\
\qquad(2013)\end{array}$ \\
\hline $\begin{array}{c}\text { Fatores } \\
\text { Acadêmicos }\end{array}$ & $\begin{array}{l}\text { Situações que se } \\
\text { relacionam à } \\
\text { interação dos } \\
\text { discentes com } \\
\text { tutores/discentes }\end{array}$ & $\begin{array}{l}\text { Problemas de } \\
\text { relacionamento } \\
\text { com colegas de } \\
\text { curso }\end{array}$ & Principal & $\begin{array}{l}\text { O principal motivo que me fez sair do curso } \\
\text { foi o bullying [...] várias pessoas se } \\
\text { aproximaram relatando ter sofrido a mesma } \\
\text { coisa [...] discriminação pela sua classe social, } \\
\text { cor, biotipo corporal. Pessoas com deficiência, } \\
\text { sem deficiência, negras, gordas, da periferia [...] } \\
\text { dois colegas também se sentiram rejeitados. } \\
\text { Tanto que saíram do curso (E15). }\end{array}$ & E15 & $\begin{array}{l}\text { Ambiel (2015) } \\
\text { Bardagi e Hutz } \\
\quad(2009)\end{array}$ \\
\hline
\end{tabular}

Fonte: Elaboração própria baseada nos dados da pesquisa. 
Quase todas as razões principais que justificam a evasão se associam aos fatores situacionais (Almeida et al., 2013). Destes, motivos relacionados à carreira, ou seja, aqueles que versam sobre preocupações e constatações a respeito da carreira futura (Ambiel, 2015) foram os mais citados. A falta de expectativas na carreira (Bardagi \& Hutz, 2009; Santos, 2018; Silva Filho et al., 2007), mencionada também nos estudos sobre o turismo (Tomazoni, 2007), é agravada pela possibilidade de trabalhadores, com ou sem formação específica, atuarem no setor (Petrizzi et al., 2015) e, comumente, não se oferecer melhores condições empregatícias aos profissionais com qualificação superior (Rodriguez et al., 2016). Isto demanda o repensar da formação superior no Turismo e áreas afins (Sogayar \& Rejowski, 2011), voltando-se ao desenvolvimento de múltiplas competências profissionais (Catramby \& Costa, 2004; Nieves, 2010) que se coadunem às exigências do mercado (Petrizzi et al., 2015).

A dificuldade em conciliar estudo, trabalho e família, verificada em investigações distintas do campo do turismo (Almeida et al., 2013; Lamers et al., 2017), foi o segundo item mais recorrente. A alegação de E11 reforça os desafios impostos aos graduandos para permanecerem estudando, especialmente, se enfrentam dificuldades financeiras (Cardoso \& Ludovico, 2017; Xu, 2017), fato que os obriga a manterem, paralelamente, uma intensa rotina de trabalho para complementação da renda familiar (Almeida et al., 2013). Por extensão, relaciona-se, esta ocorrência, ao motivo problema financeiro relatado por E8, como um agravante para abandonar a Hotelaria. Este configura achado mais comum nas IES privadas (Ambiel et al., 2016), não obstante, na realidade de países em desenvolvimento, também seja preditor da evasão nas públicas (Netto et al., 2012), o que torna essenciais os fomentos estudantis, como financiamentos e bolsas de estudo (Melguizo et al., 2011), além de políticas públicas que favoreçam a permanência dos discentes no ensino superior (Lamers et al., 2017; Lima \& Zago, 2018; Santos, 2018).

Os motivos de ordem familiar foram citados por três investigados, sendo que, para E3 e E6, a falta de apoio de parentes, acerca do curso escolhido, respondeu pela evasão. Isto reflete a imagem negativa que a sociedade costuma ter sobre a formação na área (Sogayar \& Rejowski, 2011), além de que a sensação de inferioridade profissional, já no processo de formação, colabora para o abandono do curso (Castro et al., 2019). Além disso, E9 salientou o impacto do contexto familiar na vida do alunado, situação prevista em investigações anteriores (Ambiel, 2015; Cardoso \& Ludovico, 2017; Wickens et al., 2006).

Outros motivos principais para a evasão, que obtiveram apenas uma manifestação, referem-se a: Possui ou iniciou outro curso, reforçando o comportamento previsto por Sampaio et al. (2011) de que quando o aluno reconhece uma escolha equivocada, ele abandona o curso para tentar um novo vestibular; Intenção prévia de mudança de curso, achado deste trabalho, realça a escolha por Hotelaria ou Turismo, devido à facilidade de aprovação nos processos seletivos (Marques, Darn, \& Imamura, 2018) e às possíveis transferências futuras de curso na universidade. Este comportamento foi definido por Bardagi e Hutz (2009), como o perfil de evadidos que demonstram insatisfação com a escolha do curso desde o seu ingresso.

$\mathrm{Na}$ categoria Fatores Acadêmicos, o motivo destacado foi problemas de relacionamento com colegas de curso. Dependendo da qualidade da interação, as relações tanto podem motivar a permanência, quanto acelerar a evasão (Anastasiou, 2019; Bardagi \& Hutz, 2012; Wickens et al., 2006). O bullying sofrido por E15 é compreendido como prática comum no ambiente educacional, pode se estender desde os primeiros anos de formação até o ensino superior e ocasionar sofrimento aos estudantes (Adams \& Lawrence, 2011).

Como razões secundárias, os motivos relacionados à carreira também foram identificados como os mais recorrentes nas falas. Ou seja, dos 15 participantes da pesquisa, mais da metade (9) apontou este motivo como principal ou secundário. Esta situação reitera 
os obstáculos à atuação no setor turístico porquanto, via de regra, esbarra-se na precarização do trabalho, cujos salários tendem a ser baixos (Tomazoni, 2007), e na elevada rotatividade de mão de obra (Rodriguez et al., 2016). A concepção de que a carreira no turismo se direciona mais ao público feminino (Barcia \& Ricaurte-Quijano, 2016) e gera preconceitos também motivou o abandono do curso. O depoimento de E8 ilustra o mencionado: "fui muito criticado [...] meus familiares de piadinhas, de olhar torto. Até a questão de gênero, né? Quem vai trabalhar em hotel era mulher ou gay".

O motivo dificuldade em conciliar estudo, trabalho e família, do mesmo modo, apareceu como razão secundária, com ênfase à necessidade de superar dificuldades financeiras. Aqui, estabelece-se um paralelo com a investigação de Ferreira, Silva, Silva e Sousa (2017), para os quais mulheres costumam encontrar dificuldades em conciliar sua rotina pessoal, de estudo e trabalho, e acabam priorizando esta última. Ademais, o público feminino, normalmente, encontra suas maiores oportunidades em cargos menos prestigiados (Petrizzi et al., 2015), o que as pressiona a buscar uma formação superior. Complementarmente, no motivo possui ou iniciou outro curso, a prioridade foi dada ao curso que garante maior titulação (mestrado) (E11). Por fim, emergiu um novo motivo secundário, problema de saúde, proveniente das exigências do novo emprego de E4. Esta conjuntura já havia sido relatada por Santos, Siqueira e Mendes (2011), acerca da relação entre sofrimento e gestão afetiva do empregado com a empresa.

Questionou-se, adicionalmente, se algo poderia ter sido feito para evitar a evasão. Apenas o entrevistado E3 mencionou que sim, destacando que se houvesse apoio familiar, possivelmente não teria abandonado o curso, uma vez que "já estava encaminhado para a empresa júnior e iria ser bolsista, quando tive essa evasão". Três evadidos não souberam responder e 11 deles manifestaram que nada evitaria o abandono. Estes resultados trazem um alento, pois embora variados autores sugiram diferentes estratégias para coibir a evasão (Chen, 2012; Chim-Miki et al., 2019; Ishitani \& DesJardins, 2002; Melguizo et al., 2011; Oliveira et al., 2018; Tae-dong et al., 2017; Vitória et al., 2018; Xu, 2017), os achados sugerem que, dependendo do(s) motivo(s) central(is) (Sousa et al., 2018), dificilmente este abandono possa ser evitado, especialmente quando os discentes se mostram insatisfeitos com o curso desde o seu ingresso (Bardagi \& Hutz, 2009). Esta ocorrência foi manifestada por E2: "Eu já entrei com esse intuito de trocar. Eu usei a Hotelaria como uma porta de entrada para qualquer outro curso".

Nesse sentido, medidas prévias ao ingresso na IES possam ser necessárias, caso da identificação das condições socioeconômicas pregressas do aluno (Ishitani \& DesJardins, 2002) e da orientação vocacional no ensino médio (Bardagi \& Hutz, 2009). Ademais, inovações didático-pedagógicas, como estratégias de ensino mais ativas, mostram-se eficazes (Vitória et al., 2018), sobretudo quando se pensa o contexto do ensino do Turismo e da Hotelaria, cujas práticas dessa natureza ainda são incipientes (Brandão \& Silva, 2018).

\subsection{Momento pós-evasão}

Prévia à apresentação dos ganhos e perdas com a evasão, antecipa-se a manifestação de satisfação ou insatisfação dos entrevistados. Apenas E15 ainda não formou opinião, por ter evadido recentemente, conforme se percebe no trecho a seguir: "Se eu não tivesse saído poderia ter sido pior. Poderia ter adoecido [...] psicologicamente [...] acho que é o tempo mesmo quem vai dizer". A maioria (9) não se arrependeu da evasão, justificando a partir dos ganhos provenientes dessa decisão, consoante depoimento de E12: "Não me arrependo de ter abandonado o curso porque [...] tudo que fiz posteriormente à evasão foi bom. Me renderam 
frutos [...] não saí perdendo nada". Esta situação se coaduna aos resultados do estudo de Bardagi e Hutz (2009), de que é comum a baixa insatisfação dos discentes quanto à decisão de evadir.

Por fim, cinco entrevistados manifestaram insatisfação no tocante à decisão de abandonar o curso. O evadido E8 comprova esta assertiva: "Me arrependi [...] fiquei muito chateado, triste, porque [...] já tinha em mente o que queria fazer no meu lado profissional [...] estava por volta de $60 \%, 70 \%$ do curso finalizado". Nota-se que, quando as expectativas advindas com a evasão não se concretizam, é comum emergir um significativo sentimento de frustração (Barlem et al., 2012).

No tocante aos principais ganhos, foram criadas duas categorias - ganhos acadêmicoprofissionais, e pessoais - sendo que esta contém duas subcategorias, enquanto aquela apresenta quatro (Tabela 3).

Tabela 3 - Ganhos pós-evasão

\begin{tabular}{|c|c|c|c|c|}
\hline Categoria & $\begin{array}{l}\text { Definição } \\
\text { constitutiva }\end{array}$ & Subcategoria & Exemplo de relato & $\begin{array}{l}\text { Quem } \\
\text { citou }\end{array}$ \\
\hline \multirow{4}{*}{$\begin{array}{l}\text { Ganhos } \\
\text { Acadêmico- } \\
\text { profissionais }\end{array}$} & \multirow{4}{*}{$\begin{array}{l}\text { Refere-se a novas } \\
\text { oportunidades de } \\
\text { desenvolvimento e } \\
\text { atuação profissional } \\
\text { obtidas após a evasão }\end{array}$} & $\begin{array}{l}\text { Inserção no } \\
\text { mercado de } \\
\text { trabalho }\end{array}$ & $\begin{array}{l}\text { Em Contábeis tem mais oferta } \\
\text { de estágio (E7). } \\
\text { No setor de vendas }[\ldots] \\
\text { conquistei emprego com } \\
\text { salário [...] comissão, carteira } \\
\text { assinada (E8). }\end{array}$ & $\begin{array}{l}\text { E1/E2/E7/ } \\
\text { E8/E9/E14 }\end{array}$ \\
\hline & & $\begin{array}{l}\text { Realização } \\
\text { profissional }\end{array}$ & $\begin{array}{l}\text { Eu me sinto realizada com o } \\
\text { curso que faço agora (E5). }\end{array}$ & $\begin{array}{l}\mathrm{E} 5 / \mathrm{E} 6 / \mathrm{E} 10 \\
\quad / \mathrm{E} 13\end{array}$ \\
\hline & & $\begin{array}{l}\text { Tempo para } \\
\text { estudar }\end{array}$ & $\begin{array}{l}\text { Ganhos profissionais }[\ldots] \text { em } \\
\text { relação à formação. Após } \\
\text { evadir }[\ldots] \text { fiz curso técnico }[\ldots] \\
\text { graduação }[\ldots] \text { recentemente, } \\
\text { finalizei duas especializações } \\
(\text { E12). }\end{array}$ & E11/E12 \\
\hline & & $\begin{array}{l}\text { Oportunidades } \\
\text { oferecidas pelo } \\
\quad \text { curso }\end{array}$ & $\begin{array}{l}{[\ldots] \text { viagem, intercâmbio e }} \\
\text { pesquisa }[\ldots] \text { Turismo tem mais } \\
\text { possibilidades que Hotelaria } \\
(\mathrm{E} 2) \text {. }\end{array}$ & E2 \\
\hline \multirow{2}{*}{$\begin{array}{l}\text { Ganhos } \\
\text { Pessoais }\end{array}$} & \multirow{2}{*}{$\begin{array}{l}\text { Refere-se a melhorias } \\
\text { na vida do discente } \\
\text { relacionadas à saúde } \\
\text { e relacionamentos }\end{array}$} & $\begin{array}{l}\text { Relacionamento } \\
\text { interpessoal }\end{array}$ & $\begin{array}{l}\text { Ganhei pouquíssimas amizades } \\
{[\ldots] \text { que estão até hoje na }} \\
\text { minha vida }(\mathrm{E} 15) .\end{array}$ & E9/E15 \\
\hline & & $\begin{array}{l}\text { Melhoria de } \\
\text { saúde }\end{array}$ & $\begin{array}{l}\text { Minha saúde mental [...] estou } \\
\text { me sentindo melhor (E4). }\end{array}$ & $\mathrm{E} 4$ \\
\hline
\end{tabular}

Fonte: Elaboração própria baseada nos dados da pesquisa.

$\mathrm{Na}$ categoria ganhos acadêmico-profissionais, os principais benefícios advindos da evasão foram a inserção no mercado de trabalho, seja pela contratação ou estágio em uma organização, e a realização profissional. Os efeitos contrários ao que se esperava na formação em Turismo ou Hotelaria - oportunidades reduzidas de trabalho e renda - favoreceram essa percepção positiva. Além destas subcategorias, E11 e E12 ressaltaram disporem de mais tempo para estudar, o que propicia a qualificação continuada tão exigida nos mercados atuais (Robbins, Judge, \& Sobral, 2011). No que concerne aos ganhos pessoais, frisou-se a melhoria da saúde e dos relacionamentos interpessoais. Este último motivo costuma prorrogar a decisão de evadir (Anastasiou, 2019; Bardagi \& Hutz, 2012; Wickens et al., 2006). 
No entanto, também foram identificadas perdas no momento pós-evasão, as quais foram agrupadas também nas mesmas duas categorias. Sopesando outros fatores percebidos no pós-evasão (perdas acadêmico-profissionais), os discentes manifestaram que o distanciamento dos colegas do antigo curso e a menor afinidade com os do novo curso (perdas pessoais) geraram sentimentos negativos nesta etapa. Nos cursos estudados, os bons relacionamentos interpessoais não foram suficientes para assegurar a retenção, conforme se observa na Tabela 4.

Tabela 4 - Perdas pós-evasão

\begin{tabular}{|c|c|c|c|c|}
\hline Categoria & Definição constitutiva & Subcategoria & Exemplo de relato & $\begin{array}{l}\text { Quem } \\
\text { citou }\end{array}$ \\
\hline \multirow{2}{*}{$\begin{array}{l}\text { Perdas } \\
\text { Acadêmico- } \\
\text { profissionais }\end{array}$} & \multirow{2}{*}{$\begin{array}{c}\text { Refere-se aos prejuízos } \\
\text { de aprendizagem e } \\
\text { profissionais } \\
\text { decorrentes da não } \\
\text { conclusão do curso, } \\
\text { bem como de ausência } \\
\text { de realização } \\
\text { profissional devido à } \\
\text { evasão }\end{array}$} & $\begin{array}{l}\text { Frustração } \\
\text { profissional }\end{array}$ & $\begin{array}{l}\text { Para subir de cargo, galgar alguma } \\
\text { coisa maior }[\ldots] \text { para nossa vida } \\
\text { profissional é complicado apenas } \\
\text { com o ensino médio }[\ldots] \text { ter } \\
\text { estabilidade (E8). }\end{array}$ & $\begin{array}{l}\text { E3/E8/E9/ } \\
\text { E11 }\end{array}$ \\
\hline & & $\begin{array}{c}\text { Oportunidades que } \\
\text { seriam oferecidas } \\
\text { pelo antigo curso }\end{array}$ & $\begin{array}{l}{[\ldots] \text { perda do contato com a }} \\
\text { academia, né? Com o estudo, } \\
\text { pesquisa, com projetos }[\ldots] \text { em } \\
\text { comparação ao que, a longo prazo, } \\
\text { o curso poderia me dar, tenho } \\
\text { certeza que são muito mais } \\
\text { perdas do que ganhos }(E 8) .\end{array}$ & $\begin{array}{l}\text { E3/E7/E8/ } \\
\text { E10/E13/ } \\
\text { E15 }\end{array}$ \\
\hline $\begin{array}{l}\text { Perdas } \\
\text { Pessoais }\end{array}$ & $\begin{array}{c}\text { Refere-se aos } \\
\text { sentimentos negativos } \\
\text { decorrentes da } \\
\text { diferença de } \\
\text { relacionamentos } \\
\text { interpessoais entre os } \\
\text { cursos, além do } \\
\text { distanciamento com } \\
\text { pessoas que havia } \\
\text { afinidade }\end{array}$ & $\begin{array}{l}\text { Relacionamentos } \\
\text { interpessoais }\end{array}$ & $\begin{array}{l}\text { Foi essa a minha perda maior: } \\
\text { contato com outras pessoas [...] } \\
\text { com a coordenação, pró-reitoria, } \\
\text { toda a equipe discente e docente } \\
{[\ldots] \text { Lá (Computação) [...] as }} \\
\text { pessoas são mais frias (E1). }\end{array}$ & $\begin{array}{l}\text { E1/E2/E3/ } \\
\text { E4/E6/E9/ } \\
\text { E10 }\end{array}$ \\
\hline
\end{tabular}

Fonte: Elaboração própria baseada nos dados da pesquisa.

A subcategoria frustração profissional se refere tanto ao fato de que os evadidos possuíam afinidade com o antigo curso, quanto às dificuldades para obter melhores oportunidades profissionais, normalmente, oferecidas a graduados. Neste último caso, manifestado por E8, o abandono representou o término das aspirações para adquirir o grau universitário (Sampaio et al., 2011), fato que costuma gerar arrependimento na decisão de evadir (Barlem et al., 2012). Por último, as perdas das oportunidades que seriam oferecidas pelo antigo curso, diante da característica interdisciplinar do Turismo e da Hotelaria, que favoreceria a aquisição de conhecimentos sobre idiomas, eventos, de interação com diferentes públicos, afora o envolvimento nas atividades de ensino, pesquisa e extensão. Quando não se confirmam as expectativas geradas na mudança do curso, os estudantes tendem a se sentir insatisfeitos com a evasão (Barlem et al., 2012). 


\section{Considerações finais}

Este estudo identificou os motivos que levam à evasão de discentes dos cursos de Turismo e Hotelaria de uma universidade federal do Nordeste brasileiro, bem como investigou as suas percepções no momento pós-evasão. A maioria dos respondentes evadiu no primeiro ano do curso, confirmando a literatura específica, e não possuía Turismo ou Hotelaria como primeira opção, reforçando a predileção do alunado por cursos mais específicos e tradicionais.

A partir da diversidade de motivos levantados, reforça-se a compreensão da evasão como um fenômeno multidimensional, haja vista se ter encontrado categorias distintas Fatores Situacionais e Fatores Acadêmicos - resultando em oito diferentes subcategorias: Problema financeiro; Motivos de ordem familiar; Dificuldade em conciliar estudo, trabalho e família; Possui ou iniciou outro curso; Motivos relacionados à carreira; Intenção prévia de mudança de curso; Problemas de relacionamento com colegas de curso; Problema de saúde. Diferentemente dos estudos sobre $\mathrm{EaD}$, as categorias Fatores tecnológicos $e$ de infraestrutura, e Fatores Administrativos não foram identificadas na realidade dos cursos presenciais estudados.

Considerando a quantidade de menções feita pelos entrevistados (motivos principais e secundários), pode-se dizer que as razões mais significativas para evadir foram:

(a) Motivos relacionados à carreira (9) - a falta de expectativas profissionais do turismólogo/hoteleiro, sobretudo no que concerne a oportunidades empregatícias e remuneração justa, motivou a evasão;

(b) Dificuldade em conciliar estudo, trabalho e família (5) - a necessidade de compatibilizar diferentes rotinas é agravada pelas condições financeiras dos evadidos. Mesmo que a investigação tenha ocorrido em uma universidade pública, a realidade econômica de alguns estudantes motivou direta ou indiretamente a evasão, igualando este resultado ao encontrado, comumente, nas IES privadas;

(c) Possui ou iniciou outro curso (4) - os que mencionaram este motivo (E4 e E11) já possuíam outra formação em nível superior, optando, por conseguinte, pelo trabalho e pela pós-graduação, respectivamente. Além disso, reconhecer a falta de valorização da profissão contribuiu na decisão de evadir e mudar de curso, conforme fizeram E1 e E12;

(d) Motivos de ordem familiar (3) - representados, especialmente, pela falta de apoio familiar, repercutiram na evasão e refletem o preconceito com essas formações, além da insegurança do alunado em permanecer no curso.

Como percepções do pós-evasão, a maioria dos investigados se sente satisfeita com a evasão e elenca como principais ganhos acadêmico-profissionais a inserção no mercado de trabalho, realização profissional, tempo para estudar e oportunidades oferecidas pelo curso. Os principais ganhos pessoais foram os relacionamentos interpessoais e a melhoria da saúde. Quanto às perdas acadêmico-profissionais se destacaram a frustração profissional e as oportunidades que seriam oferecidas pelo antigo curso, enquanto as perdas pessoais foram os relacionamentos interpessoais.

A partir do mapeamento dos motivos da evasão, são apresentadas algumas contribuições gerenciais para minimizar esta prática. Recomenda-se: i. Orientações vocacionais no ensino fundamental e médio, para que os discentes tomem decisões de carreira mais conscientes; ii. Acompanhar, preventivamente, alunos com características preditivas à 
evasão; iii. Oferecer suporte financeiro aos estudantes de baixa renda, para que possam se dedicar integralmente ao curso; iv. Promover, desde o ingresso, o engajamento discente nas atividades acadêmicas, favorecendo a compreensão das possibilidades de atuação profissional e, consequentemente, seu interesse na formação; v. Elaborar PPCs condizentes com as demandas atuais e futuras do mercado de trabalho; vi. Implantar nas IES estratégias de ensino-aprendizagem mais ativas e inovadoras que reduzam os gaps de competências e promovam o estreitamento entre teoria e prática; vii. Fomentar espaços de debate que promovam a inclusão e o respeito à diversidade, coibindo o bullying .

Como limitações de pesquisa são destacadas: i. Escassez de estatísticas de evasão sobre os cursos investigados, tanto na IES quanto nos órgãos oficiais da educação superior; ii. Número de discentes investigados, diante do universo de evadidos e a dificuldade de contactar muitos destes; iii. Impossibilidade de generalização dos dados, pois se trata de uma pesquisa qualitativa no contexto de uma universidade pública do Nordeste brasileiro.

Como agenda de pesquisa, sugere-se: i. Investigar o tema da evasão nos cursos de Turismo e Hotelaria, em diferentes níveis de formação (técnico, tecnólogo, bacharel, e pósgraduação stricto sensu), em outras IES públicas e privadas, bem como outros cursos de diferentes campos do conhecimento; ii. Desenvolver estudos quantitativos sobre evasão com aplicação de instrumentos validados que considerem as variáveis identificadas nesta pesquisa, ou incorporando outras; iii. Realizar investigações qualitativas que envolvam outras técnicas de análise e coleta de dados; iv. Pesquisar outros temas relacionados à evasão como o engajamento na permanência discente, com levantamento de tendências de evasão, e identificação de estratégias desenvolvidas pelas IES para mitigar a evasão e ampliar a retenção; e v. Realizar estudos comparativos entre diferentes cursos ou de um mesmo curso em diferentes estados/regiões do Brasil, e em diferentes níveis de formação, para verificar se há diferenças nos motivos de evasão em cada caso.

Por último, reforça-se que os resultados obtidos junto aos discentes evadidos nos últimos dez anos subsidiam a definição de estratégias e de políticas para o ensino superior que coíbam a evasão e viabilizem um número maior de conclusões nos cursos. Estas ações são fundamentais para mitigar a ociosidade de vagas e o consequente desperdício dos recursos investidos, ao mesmo tempo que garante a oferta de profissionais em quantidade e qualidade necessárias à adequada prestação de serviços turísticos no país.

\section{Referências}

Adams, F.D. \& Lawrence, G.J. (2011). Bullying Victims: The Effects Last Into College. American Secondary Education, 40(1): 4-13.

Almeida, O.C.S., Abbad, G.A., Meneses, P.P.M., \& Zerbini, T. (2013). Evasão em cursos à distância: fatores influenciadores. Revista Brasileira de Orientação Profissional, 14(1): 1933.

Ambiel, R.A.M. (2015). Construção da escala de motivos para evasão do ensino superior. Avaliação Psicológica, 14(1): 41-52.

Ambiel, R.A.M., Carvalho, L.F., Moreira, T.C., \& Bacan, A.R. (2016). Funcionamento diferencial dos itens na escala de motivos para evasão do Ensino Superior (M-ES). Psico, 47(1): 68-76.

Anastasiou, M. (2019). Mapping International Students' Expectations From The Cy Hospitality And Tourism Higher Education: An Early Dropout Indicator. Tourism and Hospitality Management, 25(2): 269-290. 
Aranha, K.C. \& Rocha, F.D.C. (2014). Reflexões acerca do Ensino no Curso Superior de Turismo: Realidade, Desafios e Tendências. RITUR, 4(2): 67-76.

Baggi, C.A.S. \& Lopes, D.A. (2011). Evasão e avaliação institucional no ensino superior: uma discussão bibliográfica. Avaliação, 16(2): 355-374.

Barcia, J.B. \& Ricaurte-Quijano, C. (2016). Mujeres en Turismo: Equidad de género en la docencia e investigación en el área de Guayaquil, Ecuador. Estudios y Perspectivas en Turismo, 25(3): 255-278.

Bardagi, M.P. \& Hutz, C.S. (2009). Não havia outra saída: percepção de alunos evadidos sobre o abandono do curso superior. Psico-USF, 14(1): 95-105.

Bardagi, M.P. \& Hutz, C.S. (2012). Rotina Acadêmica e Relação com Colegas e Professores: Impacto na Evasão Universitária. PSico, 43(2): 174-184.

Bardin, L. (2011). Análise de Conteúdo. Ed.rev.ampl. São Paulo: Edições 70.

Barefoot, B.O. (2004). Higher education's revolving door: confronting the problem of student dropout in US colleges and universities. Open Learning, 19(1): 9-18.

Barlem, J.G.T., Lunardi, V.L., Bordignon, S.S., Barlem, E.L.D., Lunardi Filho, W.D., Silveira, R.S., \& Zacarias, C.C. (2012). Opção e evasão de um curso de graduação em enfermagem: percepção de estudantes evadidos. Revista Gaúcha Enfermagem, 33(2): 132138.

Brandão, J.F. \& Silva, A.B. (2018). Dejando Volar la Imaginación: El uso de la historieta como estrategia de enseñanza en hotelería. Estudios y Perspectivas en Turismo, 27(2): 233255.

Brasil. (1996). Comissão Especial de Estudos sobre a evasão nas Universidades Públicas Brasileiras. Diplomação, retenção e evasão nos cursos de graduação em instituições de ensino superior públicas. Brasília: ANDIFES; ABRUEM; SESu, MEC: 35p.

Cardoso, D.F. \& Ludovico, N. (2017). Estudo longitudinal sobre as pesquisas de evasão no ensino superior: Diretório IBICT. REFAS, 3(4): 1-18.

Castro, P.A., Souza, T.S., \& Sá, S. (2019). Evasão no ensino superior: mapeamento de cursos licenciaturas da Universidade Federal de Goiás. Revista EDaPECI, 18(3): 45-60.

Catramby, T.C. \& Costa, S.R.R. (2004). Qualificação Profissional em Turismo como Fatorde Competitividade do Setor. Caderno Virtual de Turismo, 4(3): 26-34.

Chim-Miki, A.F., Campos, D.B., \& Melo, L.S.A. (2019). Definindo espaços de educação criativa no Ensino Superior de Administração através de mecanismos de cocriação de valor. Administração: Ensino e Pesquisa, 20(2): 1-22.

Ferreira, L., Silva, A., Silva, D., \& Sousa, T. (2017). Mulheres em cargos de gerência e os desafios em conciliar vidas pessoal e profissional: um estudo em hotéis de São Luís-MA, Brasil. Revista Turismo \& Desenvolvimento, 27/28: 2279-2289.

Flick, U. (2009). Introdução à pesquisa qualitativa. $3^{\mathrm{a}}$ ed. Porto Alegre: Artmed: 405p.

Fontanella, B.J.B., Ricas, J., \& Turato, E.R. (2008). Amostragem por saturação em pesquisas qualitativas em saúde: contribuições teóricas. Caderno de Saúde Pública, 24(1): 17-27.

Ishitani, T.T. \& DesJardins, S.L. (2002). A Longitudinal Investigation of Dropout from College in the United States. Journal College Student Retention, 4(2): 173-201.

Instituto Nacional de Estudos e Pesquisas Educacionais Anísio Teixeira [INEP]. (2016). Sinopse Estatística da Educação Superior 2015. Brasília, Inep.

Instituto Nacional de Estudos e Pesquisas Educacionais Anísio Teixeira [INEP]. (2019). Sinopse Estatística da Educação Superior 2018. Brasília, Inep.

Lamers, J.M.S., Santos, B.S., \& Toassi, R.F.C. (2017). Retenção e evasão no ensino superior público: estudo de caso em um curso noturno de odontologia. Educação em Revista, (33): $1-26$. 
Lima, F.S. \& Zago, N. (2018). Desafios conceituais e tendências da evasão no ensino superior: a realidade de uma universidade comunitária. Revista Internacional de Educação Superior, 4(2): 366-386.

Marques, W., Darn, T., \& Imamura, M. (2018). O profissional do Turismo - formação superior e trabalho. Revista Eletrônica de Educação, 12(2): 336-344.

Melguizo, T., Torres, F.S., \& Jaime, H. (2011). The association between financial aid availability and the college dropout rates in Colombia. High Education, 62(2): 231-247.

Mota, K.C.N. \& Anjos, F.A. (2012). Educação superior em turismo no Brasil: Análise da oferta de cursos superiores no Nordeste brasileiro pelos institutos federais. Revista Brasileira de Pesquisa em Turismo, 6(1): 48-63.

Netto, C., Guidotti, V., \& Santos, P.K. (2012). A evasão na EAD: investigando causas, propondo estratégias. Anais da Conferencia Latinoamericana sobre el Abandono en la Educación Superior, 2, CLABES.

Nieves, S.G. (2010). La experiencia de un diseño curricular en turismo basado en un modelo por competencias profesionales. Estudios y Perspectivas en Turismo, 19(1): 139-156.

Oliveira, P.R., Oesterreich, S.A., \& Almeida, V.L. (2018). Evasão na pós-graduação à distância: evidências de um estudo no interior do Brasil. Educação e Pesquisa, 44(e165786): 1-20.

Petrizzi, R.S., Ollero, J.L.S., \& Pozo, A.F.G. (2015). Desajuste Educativo: situación actual e implicancias en el sector hotelero del Noroeste argentino. Estudios y Perspectivas en Turismo, 24(3): 470-492.

Pimentel, T., Carvalho, F., \& Pimentel, M. (2017). Mapeamento da Oferta Educacional e das Estruturas Formais de Pesquisa em Turismo no Brasil. Revista Turismo \& Desenvolvimento, 27/28: 1771-1784.

Robbins, S.P., Judge, T.A., \& Sobral, F. (2011). Comportamento Organizacional. $14^{a}$ ed. São Paulo: Pearson Prentice Hall.

Sampaio, B., Sampaio, Y., Melo, E.P.G., \& Melo, A.S. (2011). Desempenho no Vestibular, Background Familiar e Evasão: Evidências da UFPE. Economia Aplicada, 15(2): 287-309.

Santos, M.A.F., Siqueira, M.V.S., \& Mendes, A.M. (2011). Sofrimento no trabalho e imaginário organizacional: ideação suicida de trabalhadora bancária. Psicologia \& Sociedade, 23(2): 359-368.

Santos, V.M. (2018). Estilos de aprendizagem no Ensino Superior: enfrentando a evasão e a retenção. Práxis Educativa, 13(2): 578-595.

Santos Jr., J.S \& Real, G.C.M. (2017). A evasão na educação superior: o estado da arte das pesquisas no Brasil a partir de 1990. Avaliação, 22(2): 385-402.

Silva, G.P. (2013). Análise de evasão do ensino superior: uma proposta de diagnóstico de seus determinantes. Avaliação, 18(2): 311-333.

Silva Filho, R.L.L., Motejunas, P.R., Hipólito, O., \& Lobo, M.B.C.M. (2007). A evasão no ensino superior brasileiro. Cadernos de Pesquisa, 37(132): 641-659.

Sogayar, R.L. \& Rejowski, M. (2011). Ensino Superior em Turismo em Busca de Novos Paradigmas Educacionais: problemas, desafios e forças de pressão. Revista Turismo Visão e Ação-Eletrônica, 13(3): 282-298.

Sousa, A.S.Q., Mártires, H., \& Sousa, C. (2018). Motivos para evadir da Escola Superior de Educação e Comunicação da Universidade do Algarve/Portugal, segundo os estudantes. Revista Educação em Questão, 56(47): 43-70.

Sousa, E.N. \& Tomazzoni, E.L. (2017). El Análisis de Contenido en las Investigaciones Turísticas en Brasil: ¿Qué muestran las revistas brasileñas de turismo? Estudios y Perspectivas en Turismo, 26(1): 42-61. 
Tae-dong, K., Min-young, Y., Jinhwa, B., Byoung-a, M., Inseong, L., \& Jinwoo, K. (2017). Escape from infinite freedom: Effects of constraining user freedom on the prevention of dropout in an online learning context. Computers in Human Behavior, 66: 217-231.

Tomazoni, E.L. (2007). Educação Profissional em Turismo: Cria-se Mercado pela Formação? Turismo em Análise, 18(2): 197-219.

Vitória, M.I.C., Casartelli, A., Rigo, R.M., \& Costa, P.T. (2018). Engajamento acadêmico: desafios para a permanência do estudante na Educação Superior. Educação, 4(2): 262-269.

Xu, Y.J. (2017). Localizing College Retention Efforts: The Distance between Theoretical Orientation and Institution-Specific Needs. Innovative Higher Education, 42: 49-63.

Wickens, E., Forbes. A., \& Tribe, J. (2006) Listening, Understanding and Responding to Leisure and Tourism Undergraduates. Journal of Hospitality, Leisure, Sport and Tourism Education, 5(2): 4-13.

Ziliotto, D.M., Souza, D.J., \& Andrade, F.I. (2018). Quando a inclusão não se efetiva: a evasão de alunos surdos ou com deficiência auditiva no ensino superior. Revista Educação Especial, 31(62): 727-740. 